\title{
NEW BEARING SURFACES IN TOTAL HIP REPLACEMENT
}

Carlos Roberto Schwartsmann', Leonardo Carbonera Boschin², Ramiro Zilles Gonçalves², Anthony Kerbes Yépez², Leandro de Freitas Spinelli²

\section{ABSTRACT}

Total hip arthroplasty is being increasingly indicated for younger and more active patients, in addition to a naturally growing demand for the procedure because of increasing life expectancy among patients. The high costs of this surgery and the controversies regarding implant performance have made this topic the subject of constant research, seeking new materials with better resistance to wear and better biocompatibility. The present article provides a review of new surfaces in total hip arthroplasty.

Keywords - Arthroplasty, Replacement, Hip/history; Arthroplasty, Replacement, Hip/methods; Arthroplasty, Replacement, Hip/statistics \& numerical data.

\section{INTRODUCTION}

Total hip arthroplasty continues to be one of the most successful orthopedic procedures. Nevertheless, the field of hip surgery faces the constant challenge of continual increases in patient volume and costs, along with controversy regarding the reliability and performance of implant surfaces ${ }^{(1,2)}$. This procedure is being increasingly indicated for younger and more active patients. The results from hip arthroplasty have been shown to be excellent in older patients. However, in younger patients ( $<40$ years), the five-year failure rates are between 21 and $28 \% \%^{(3-7)}$. Because of increasing life expectancy among the population, it is expected that arthroplastic surgery will become even more common over the coming decades. According to a recent survey by the Brazilian Institute for Geography and Statistics (IBGE), the population aged 65 years and over will increase by at least 3.7 -fold by $2050^{(8)}$.

In the form known today, total hip arthroplasty began in the 1960s, when Charnley suggested using a femoral nail with a stainless steel head jointed to a high-density polyethylene acetabular implant, with both of them fixed to the bones using polymethylmethacrylate cement. However, many problems remain unresolved, even today. An ideal mechanical model is sought, with better materials, resistance to wear and biocompatibility ${ }^{(1,9)}$. Despite continual research on better implant materials, the classical combination of metal jointed to ultra-high molecular weight polyethylene continues to be the one that is most widely used ${ }^{(1)}$.

New materials, including new alloys used in metalto-metal surfaces, ceramic materials and new types of polyethylene, have been developed and refined over the years. The present study reviews the surfaces used in cases of total hip arthroplasty.

\section{Polyethylene}

The metal-to-polyethylene surface is still the one most used in total hip arthroplasty ${ }^{(1,9)}$. Its advantage is that it is inexpensive; it is technically easier to implant; it allows immediate load-bearing; surgeons have wide experience with this method; and present-day acetabula made of cross-linked polyethylene will bring better future results than seen with older types of polyethylene. Its disadvantages are that the cement

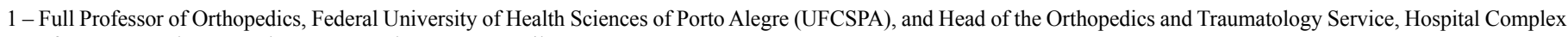
of Santa Casa de Porto Alegre, Porto Alegre, RS, Brazil.

2 - Hip Surgery Group, Hospital Complex of Santa Casa de Porto Alegre, Porto Alegre, RS, Brazil.

Work performed in the Hospital Complex of Santa Casa de Porto Alegre, Porto Alegre, RS, Brazil.

Correspondence: Rua Leopoldo Bier 825, Santana, 90620-100 Porto Alegre, RS. E-mail: schwartsmann@gmail.com

Work received for publication: September 12, 2011; accepted for publication: September 15, 2011.

The authors declare that there was no conflict of interest in conducting this work 
ages and then disintegrates, which may give rise to the well-known "cement disease". This surface shows greater wear than is seen with newer surfaces, and the particles thus produced may, in addition to "polyethylene disease", also cause osteolysis ${ }^{(1)}$. Berry et al ${ }^{(10)}$ showed survivals rate of $92 \%$ after a 10 -year follow-up and $77.5 \%$ after a 25 -year follow-up, among patients with conventional Charnley prostheses. Schulte et $a l^{(11)}$, Keener et $a l^{(12)}$, Callaghan et $a l^{(13)}$ and $\mathrm{Bu}-$ ckwalter et $a l^{(14)}$ presented rates of good results from using the Charnley prosthesis ranging from $69 \%$ to $90 \%$, after 20 to 30 years of follow-up. Wroblewski et $a l^{(15)}$ reported on an even longer follow-up period (30 to 40 years) of Charnley prosthesis use, with $90 \%$ presenting good results.

Ultra-high molecular weight polyethylene is formed by means of polymerization of ethylene and is especially good for orthopedic implants, give that it is biocompatible, provides a low-friction surface and is notably resistant to wear ${ }^{(9)}$. Charnley started to use it in 1962 after having rejected Teflon as a material for acetabular implants on the grounds that it presented very low resistance and a high rate of wear ${ }^{(1)}$.

Polyethylene wear is the biggest obstacle to prosthesis longevity. Young and active patients, and especially male patients under the age of 55 years, are the ones who present greater risk of accelerated wear ${ }^{(1)}$. Cross-linked polyethylene is obtained by means of a process of irradiating polyethylene with gamma rays. The irradiation of the material produces "cross-bonding" in the molecular structure of the material. The polyethylene is then subjected to heating up to a few degrees below the melting point, for a precise period of time, in order to remove the free radicals.

Cross-linking of polyethylene combined with thermal treatment has emerged recently as a technology for improving the resistance of polyethylene against wear and oxidation of ultra-high molecular weight polyethylene (UHMWPE) acetabular components. Cross-linking is certainly not a new technology, because most conventional bearing surfaces made of UHMWPE have always been sterilized using gamma irradiation. The typical scale of radiation dose for gamma sterilization is $25-40 \mathrm{kGy}$, which leads to sterilization of the product and some degree of crosslinking. Consequently, the majority of acetabula made of UHMWPE that have been used over the last four decades have always had some degree of cross- linking. However, the level of cross-linking achieved through gamma sterilization alone is much lower than what is being done using more up-to-date irradiation methods followed by a thermal treatment stage. The changes to the mechanical properties of thermally treated polyethylene occur primarily through changes to its density and crystallinity ${ }^{(9)}$.

Although polyethylene failure may occur because of external fracturing or wear, the most common type of polyethylene failure is internal wear at the metal-plastic interface. This wear occurs more frequently in the superolateral portion of the component, and the determining factors are the coefficient of friction, lubrication, load applied, diameter of the head, number of cycles and hardness of the materials ${ }^{(1)}$. There are three types of wear: abrasive wear, in which the harder surface produces grooves on the softer surface; adhesive wear, in which the softer material releases fragments that adhere to the harder material; and fatigue, in which cyclical loading gives rise to fissures, particles or delamination and the material goes beyond the elastic regime, thus causing plastic rupture ${ }^{(16)}$.

According to Huo et $a l^{(2)}$, cross-linked polyethylene has been used for more than a decade, and its wear resistance characteristics have been continually studied. The presence of osteolysis in young patients ( $<50$ years) with total arthroplasty using polyethylene with cross-linking is lower than among those treated using polyethylene without cross-linking. Regarding the relationship between cross-linked polyethylene wear and osteolysis, the penetration rate into the femoral head has not been found to differ between the different sizes evaluated (36, 38 and $40 \mathrm{~mm})$. Likewise, Huo et $a l^{(2)}$ stated that the rates found for the head sizes 28 and $32 \mathrm{~mm}$ also did not differ $(\mathrm{p}=0.48)$. This is important because larger heads have been used to improve the clinical performance of implants and reduce the risk of dislocation. These authors reported that fracturing of the material due to fatigue was a potential limitation of first-generation cross-linked polyethylene, but that such materials could be expected in the future to provide better resistance and lower risk of fracturing due to fatigue ${ }^{(2)}$.

\section{Metal}

The biggest advantage of using metal-to-metal surfaces in total hip arthroplasty is the reduction in wear. A conventional polyethylene acetabulum has 
an average wear rate of $0.1 \mathrm{~mm}$ to $0.2 \mathrm{~mm}$ per year. Metal-to-metal joints have wear rates that may be 40 to 100 times lower $^{(17,18)}$. Likewise, the volumetric wear rate of metal-to-metal joints is approximately 200 times lower than that of metal-to-polyethylene joints ${ }^{(17,18)}$, but the mean values found in the literature vary. General averages for linear wear can be seen in Figure 1 for different combinations of joint surfaces, and Figure 2 shows some examples of different joint surfaces.

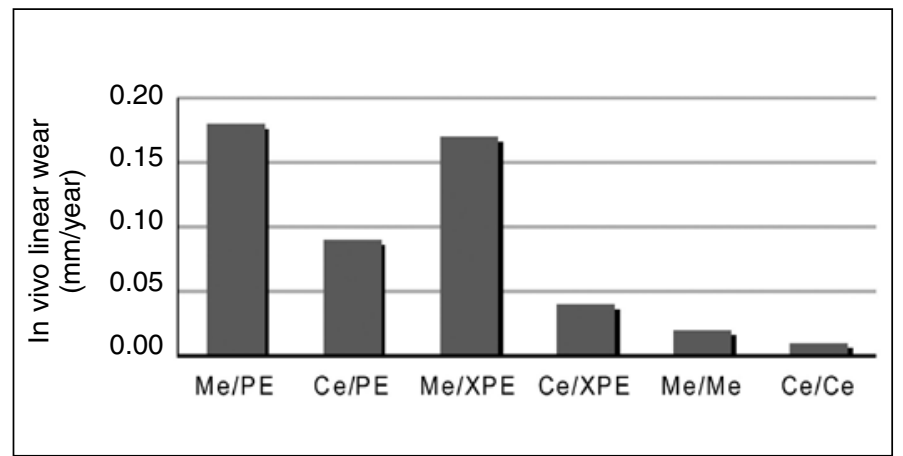

Figure 1 - Mean rates of in vivo linear wear per year for the head-acetabulum configurations found in orthopedic practice. $\mathrm{Me}=$ metal; $\mathrm{PE}=$ polyethylene; $\mathrm{Ce}=$ ceramic; $\mathrm{XPE}=$ cross-linked polyethylene.
The disadvantages of metal-to-metal joints include their high cost, patient hypersensitivity to metal, lack of long-term clinical trials and release of metal ions (cobalt, chromium and titanium), which have been detected both in blood and in urine, and both in new and in old designs ${ }^{(19,20)}$. Abnormal levels of these ions have also been observed in relation to metal-to-polyethylene joints, but these variations are much lower. Huo et $a l^{(2)}$ reported that the most controversial point regarding the biological response of new surfaces was in relation to metal-to-metal surfaces. They reported that increasing numbers of studies involving metal-to-metal joints had presented potential adverse effects and they discussed whether these effects could be involved both in cases of total hip arthroplasty with large-diameter metalto-metal surfaces and in cases of resurfacing. The commonest problem has been the biological response of macrophages and lymphocytes, which may be related to poor implant positioning, thereby resulting in increased wear and consequent release of metal ions $^{(2)}$. Harkess and Crockarell ${ }^{(1)}$ reported that flexing
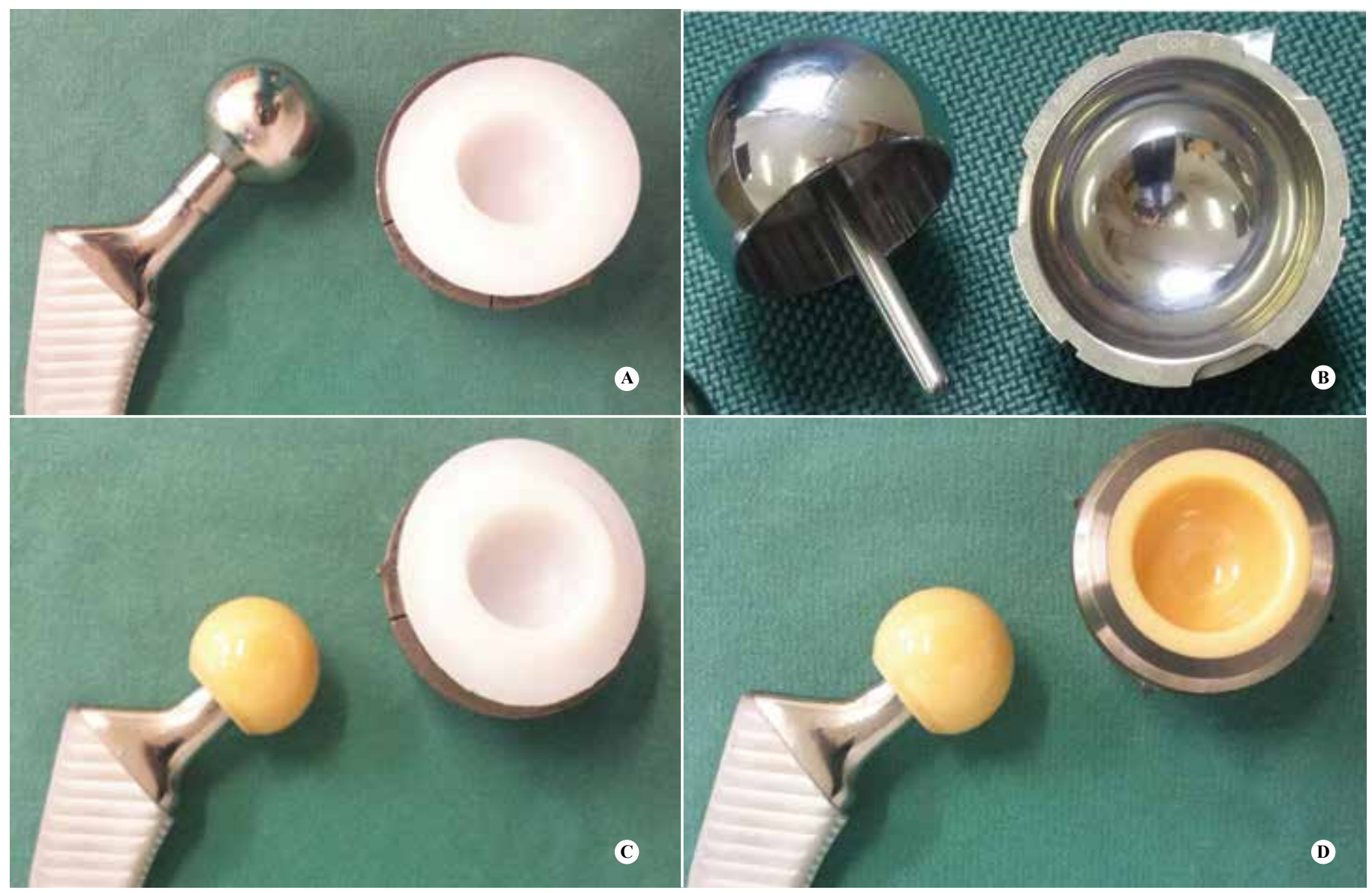

Figure 2 - Joint surfaces: (A) metal-to-polyethylene; (B) metal-to-metal; (C) ceramic-to-polyethylene; (D) ceramic-to-ceramic. 
or scratching the implant could break its protective surface covering and corrosion could accelerate the process of failure due to fatigue. The results from corrosion can be seen as formation of rubble or stains on the implant surface.

However, there is still no definitive information about the prevalence of these adverse effects relating to metal-to-metal surfaces in cases of total hip arthroplasty $^{(2)}$. Clinically, the most important adverse effect manifested is pain. Glyn-Jones et $a l^{(21)}$ conducted a study on 1,224 patients who underwent resurfacing arthroplasty. Of these, $1.8 \%$ underwent revision, mainly to treat pseudotumors. These authors observed that there was a higher chance of developing pseudotumors among female patients $(p<0.001)$, patients aged under 40 years $(p=0.003)$, cases with smaller-sized components $(p=0.003)$ and cases of hip dysplasia $(p=0.019)$. The eight-year revision rates were $0.5 \%$ for men, 6\% for women aged over 40 years and $13.1 \%$ for younger women. However, Huo et al ${ }^{(2)} \mathrm{ci}-$ ted different statistics, and reported a revision rate of around $3.2 \%$. The commonest cause of revision was fractures of the femoral neck (1.6\%) and not adverse tissue reactions or pain of unexplainable origin, with a pseudotumor prevalence rate ranging from $0.09 \%$ to $0.15 \%$ in cases of resurfacing arthroplasty.

Huo et $a l^{(2)}$ reported that histological abnormalities were associated with failure of metal-to-metal joints in resurfacing cases. Lymphocyte infiltrates may be present in the bone in up to one third of the samples: this is more frequent in women and may be the cause of pain. These abnormalities cause hypersensitivity and may lead to loss of fixation at the bone-cement interface.

Differing from the other authors cited above, Kwon et $a l^{(22)}$ evaluated tissues involved in revision surgery on metal-to-metal arthroplasty, with and without pseudotumor abnormalities, and did not find any significant differences in lymphocyte activity or traces of metal. Thus, there is some controversy regarding whether formation of these pseudotumors is related to hypersensitivity to metal ions.

Garbuz et $a l^{(23)}$ conducted a prospective randomized study comparing resurfacing arthroplasty with total hip arthroplasty using large-head metal-to-metal joints, and measured the serum cobalt and chromium levels in 30 patients. A greater increase in metal ions was observed among patients treated with total hip arthroplasty than in the group with resurfacing, and the levels in both groups were higher than before the operation.

Some studies have also shown appreciable levels of metal ions in the placenta and blood of pregnant women who had previously undergone operations with metal-to-metal surfaces ${ }^{(2)}$. Caution is therefore required in using metal-to-metal implants in women of fertile age, given that the effects of these ions in maternal and fetal blood are unknown. In a general manner, the significance (if any) of elevated metal ion levels remains uncertain. There are even some authors ${ }^{(24)}$ who have not observed any increase in specific risk to patients. Long-term studies with follow-up duration similar to studies on metal-to-polyethylene joints are not yet available for metal-to-metal joints. So far, no cause-effect relationship has been defined for metalto-metal implants, which were first implanted in the $1960 \mathrm{~s}$, or the risk of cancer $^{(7,25)}$.

\section{Ceramic}

The history of using ceramic materials for hip arthroplasty began in the 1970s. Boutin advanced the use of ceramic-to-ceramic joints subsequent to Shikata's proposal to use a ceramic femoral head that would form a joint with an acetabulum made of UHMWPE. The determining factors for these approaches were the high corrosion resistance and biocompatibility of ceramic, along with its greater resistance to scratching than shown by metal alloys. The resistance to wear of the ceramic-to-ceramic configuration is better than that of the conventional $\mathrm{CoCr} / \mathrm{UHMWPE}$ joint. The initial applications of ceramic in hip prostheses exclusively used alumina $\left(\mathrm{Al}_{2} \mathrm{O}_{3}\right)$. In the $1980 \mathrm{~s}$, zirconia $\left(\mathrm{ZrO}_{2}\right)$ was introduced for use in the femoral component of ceramic/UHMWPE prostheses because of its higher strength and resistance, compared with alumina. Since ceramic components are stable oxides, they are chemically inert and do not undergo the oxidative wear processes that can produce surface roughness on metal heads. Ceramics do not decompose to produce metal ions ${ }^{(1,9)}$.

Ceramics have the advantage that they are extremely rigid while presenting a surface of low roughness. Consequently, ceramic-to-polyethylene implants will have a greater tendency to suffer wear, in comparison with metal-to-polyethylene joints, especially with regard to their use in young and active patients ${ }^{(26)}$. As can be seen in Figure 1, even lower rates are found 
with ceramic-to-ceramic implants. Consequently, no excessive quantities of debris or ions will be observed. Therefore, surgeons can choose to use large heads in order to reduce the risk of dislocation ${ }^{(2)}$. The disadvantages of ceramic acetabula include the fact that the domes do not incorporate flanges to diminish the risk of dislocation. Moreover, they are fragile and easily broken: the first generation gave rise to catastrophic breakages. There have been significant improvements in manufacturing processes over the last few years, with decreased grain size and increased density, along with better quality control ${ }^{(9)}$. Nevertheless, today, femoral head fractures are very rare. Heisel et $a l^{(27)}$ reported a rate of $0.004 \%$. Lastly, ceramic-to-ceramic implants are more expensive ${ }^{(2)}$.

While metal bearing surfaces may become scratched in the presence of a third body, thereby increasing the wear on the polyethylene surface, ceramic bearing surfaces may theoretically remain free from scratches, for longer in vivo survival. There is controversy regarding the benefits of ceramic components for improving the in vivo wear behavior of the polyethylene. Studies have suggested that the arthroplasty has longer survival when a ceramic-to-ceramic joint rather than a ceramic-to-polyethylene joint is used ${ }^{(9)}$.

Huo et $a l^{(2)}$ reported that total hip arthroplasty with this type of surface has a 10 -year survival rate of $96 \%$, versus $91 \%$ in cases with a metal-to-polyethylene surface. However, several other authors have achieved good results in up to $90 \%$ of the cases using a metal-to-polyethylene surface, with 20 to 30 years of follow-up ${ }^{(11)}$. Wroblewski et al ${ }^{(15)}$ reported on an even longer follow-up period (30 to 40 years) for Charnley prostheses, with good results in $90 \%$ of the cases. Studies on ceramic surfaces have not yet reached this length of follow-up.

Huo et $a l^{(2)}$ reported that fractures of the dome occurred in $0.2 \%$ of the cases and that sound abnormalities occur in $0.1 \%$ of the cases. The phenomenon of squeaking has been reported in association with all types of surfaces, but it has become more commonly known in the ceramic-to-ceramic association. Different "squeaking rates" have recently been observed in association with different nail designs but with identical ceramic-to-ceramic surfaces. The acoustic characteristics differ greatly between different designs. Moreover, it has also been reported that the squeaking differs according to the number of cycles tested. Jarrett et $a l^{(26)}$ observed that the incidence of squeaking in ceramic-to-ceramic associations may be much greater than the previously reported rate of $<$ $1 \%$. The causes and implications of the phenomenon still need to be determined better.

Hernigou et $a l^{(28)}$ presented Oxinium ${ }^{\circledR}$ as a new alternative. Furthermore, a zirconium-niobium alloy $\left(\mathrm{Zr}_{2} \mathrm{Nb}_{5}\right)$ was recently introduced for hip arthroplasty. This presents the advantage that the metal surface can be transformed into a thin layer of zirconium oxide (a ceramic material), thus combining the benefits of ceramics and metals in a single component. Laboratory studies have demonstrated its theoretical superiority due to low wear in relation to polyethylene.

\section{Surfaces for coating}

Although tantalum does not form part of joint surfaces, it is a material that needs to be taken into consideration in this study. It is a metal that presents unique properties: it has high porosity (70 to $80 \%$ ), low module of elasticity ( $3 \mathrm{MPa})$ and high friction, which enables excellent biological fixation and biocompatibility. The low module of elasticity allows a more physiological means of load transfer and preservation of the bone stock. Because of its bioactive nature and bone growth stimulation properties, it is used both in primary surgery and in revisions. Long-term clinical studies and basic science studies remain necessary ${ }^{(29,30)}$. Jafari et al $l^{(31)}$ conducted a retrospective study on 283 patients who had undergone revision of arthroplasty using uncemented tantalum or titanium domes. The performance of tantalum was better.

Another technology that has been greatly used for coating acetabular and femoral components involves hydroxyapatite. This material is the main inorganic component of bones and this favors bone growth and fixation of uncemented prostheses. Paulsen et $a l^{(32)}$ presented a medium-term follow-up study on 4,125 acetabula coated with hydroxyapatite and 7,737 uncoated acetabula, and 3,158 coated femoral nails and 4,749 uncoated nails, from Danish records, and concluded that coating the implants was not associated with reduced risk of revision of arthroplasties, in comparison with uncoated implants. Lazarinis et $a l^{(33)}$ questioned the routine use of acetabular components coated with hydroxyapatite in cases of primary total hip arthroplasty. These authors investigated 8,043 cases of arthroplasty in the Swedish records and showed that some designs even increased the risk of 
loosening. Gandhi et $a l^{(34)}$ performed a meta-analysis on the use of hydroxyapatite in femoral components in cases of primary arthroplasty, and concluded that there was no benefit from using hydroxyapatite on the isolated porous coating, in primary arthroplasty. Camazzola et $a l^{(35)}$ confirmed these findings in a study on 61 patients with 13 years of follow-up. Nonetheless, long-term studies are still necessary.

\section{FINAL REMARKS}

Joint surfaces should be made of materials that have high resistance, low wear, resistance to corrosion and low friction, as well as being biocompatible. Researchers are continuing to make efforts towards achieving these objectives. Studies on these new materials and refinements of existing materials are awaited.

\section{REFERENCES}

1. Harkess JW, Crockarell JR. Arthroplasty of the hip. In: Canale ST, Beaty JH editors. Campbell's operative orthopaedics. 11th ed. Philadelphia: Mosby Elsevier, 2008. p. 312-481.

2. Huo MH, Stockton KG, Mont MA, Parvizi J. What's new in total hip arthroplasty J Bone Joint Surg Am. 2010;92(18):2959-72.

3. Duffy GP, Berry DJ, Rowland C, Cabanela ME. Primary uncemented total hip arthroplasty in patients $<40$ years old: 10 - to 14 -year results using first-generation proximally porous-coated implants. J Arthroplasty. 2001;16(8Suppl 1):140-4.

4. Chandler HP, Reineck FT, Wixson RL, McCarthy JC. Total hip replacement in patients younger than thirty years old. A five-year follow-up study. J Bone Joint Surg Am. 1981;63(9):1426-34.

5. Kim WC, Grogan T, Amstutz HC, Dorey F. Survivorship comparison of THARIES and conventional hip arthroplasty in patients younger than 40 years old. Clin Orthop Relat Res. 1987;(214):269-77.

6. Smith SE, Estok DM 2nd, Harris WH. 20-year experience with cemented primary and conversion total hip arthroplasty using so-called second-generation cementing techniques in patients aged 50 years or younger. J Arthroplasty. 2000;15(3):263-73.

7. Amstutz HC, Beaulé PE, Dorey FJ, Le Duff MJ, Campbell PA, Gruen TA. Metal-on-metal hybrid surface arthroplasty: two to six-year follow-up study. J Bone Joint Surg Am. 2004;86(1):28-39

8. Instituto Brasileiro de Geografia e Estatística - IBGE. Projeção da população brasileira por sexo e por idade. Disponível em: www.ibge.gov.br. Acesso em 24 de outubro de 2011

9. Harkess JW, Daniels AU. Introdução e visão geral. In: Canale ST, Ed. Cirurgia ortopédica de Campbell. 10a. ed. São Paulo: Manole; 2006. p.223-42.

10. Berry DJ, Harmsen WS, Cabanela ME, Morrey BF. Twenty-five-year survivorship of two thousand consecutive primary Charnley total hip replacements: factors affecting survivorship of acetabular and femoral components. J Bone Joint Surg Am. 2002;84(2):171-7.

11. Schulte KR, Callaghan JJ, Kelley SS, Johnston RC. The outcome of Charnley total hip arthroplasty with cement after a minimum twenty-year follow-up. The results of one surgeon. J Bone Joint Surg Am. 1993;75(7):961-75.

12. Keener JD, Callaghan JJ, Goetz DD, Pederson DR, Sullivan PM, Johnston RC. Twenty-five-year results after Charnley total hip arthroplasty in patients less than fifty years old: a concise follow-up of a previous report. J Bone Joint Surg Am. 2003;85(6):1066-72.

13. Callaghan JJ, Templeton JE, Liu SS, Pedersen DR, Goetz DD, Sullivan PM, et al. Results of Charnley total hip arthroplasty at a minimum of thirty years. A concise follow-up of a previous report. J Bone Joint Surg Am. 2004;86-A(4):690-5.

14. Buckwalter AE, Callaghan JJ, Liu SS, Pedersen DR, Goetz DD, Sullivan PM et al. Results of Charnley total hip arthroplasty with use of improved femoral cementing techniques. a concise follow-up, at a minimum of twenty-five years, of a previous report. J Bone Joint Surg Am. 2006;88(7):1481-5.

15. Wroblewski BM, Siney PD, Fleming PA. Charnley low-frictional torque arthroplasty: follow-up for 30 to 40 years. J Bone Joint Surg Br. 2009;91(4):447-50.

16. Israel $\mathrm{CL}$. Desenvolvimento de uma máquina para ensaios de desgaste em próteses totais de articulação de quadril [tese]. Porto Alegre: Universidade Federal do Rio Grande do Sul; 2010.

17. Willert HG, Buchhorn GH, Göbel D, Köster G, Schaffner S, Schenk R, Semlitsch M. Wear behavior and histopathology of classic cemented metal on metal hip endoprostheses. Clin Orthop Relat Res. 1996;(329 Suppl):S160-86.

18. Rieker C, Kottig P. In vivo tribological performance of 231 metal-on-metal hip articulations. Hip Int. 2002;12(2):73-6.

19. Jacobs JJ, Skipor AK, Doorn PF, Campbell P, Schmalzried TP, Black J, et al. Cobalt and chromium concentrations in patients with metal on metal total hip replacements. Clin Orthop Relat Res. 1996;(329 Suppl):S256-63.

20. Brodner W, Bitzan P, Meisinger V, Kaider A, Gottsauner-Wolf F, Kotz R. Elevated serum cobalt with metal-on-metal articulating surfaces. J Bone Joint Surg Br. 1997;79(2):316-21.

21. Glyn-Jones S, Pandit H, Kwon YM, Doll H, Gill HS, Murray DW. Risk factors for inflammatory pseudotumour formation following hip resurfacing. J Bone Joint Surg Br. 2009;91(12):1566-74.

22. Kwon YM, Thomas P, Summer B, Pandit $H$, Taylor A, Beard D, et al. Lymphocyte proliferation responses in patients with pseudotumors following metal-on-metal hip resurfacing arthroplasty. J Orthop Res. 2010;28(4):444-50.

23. Garbuz DS, Tanzer M, Greidanus NV, Masri BA, Duncan CP. The John Charnley Award: Metal-on-metal hip resurfacing versus large-diameter head metal-on-metal total hip arthroplasty: a randomized clinical trial. Clin Orthop Relat Res. 2010;468(2):318-25.

24. Visuri T, Pukkala E, Paavolainen P, Pulkkinen P, Riska EB. Cancer risk after metal on metal and polyethylene on metal total hip arthroplasty. Clin Orthop Relat Res. 1996;(329 Suppl):S280-9.

25. Tharani R, Dorey FJ, Schmalzried TP. The risk of cancer following total hip or knee arthroplasty. J Bone Joint Surg Am. 2001;83(5):774-80.

26. Jarrett CA, Ranawat AS, Bruzzone M, Blum YC, Rodriguez JA, Ranawat CS. The squeaking hip: a phenomenon of ceramic-on-ceramic total hip arthroplasty. J Bone Joint Surg Am. 2009;91(6):1344-9.

27. Heisel C, Silva M, Schmalzried TP. Bearing surface options for total hip replacement in young patients. Instr Course Lect. 2004;53:49-65.

28. Hernigou P, Mathieu G, Poignard A, Manicom O, Fillipini P, Demoura A. Oxinium, a new alternative femoral bearing surface option for hip replacement. Eur J Orthop Surg Traumatol. 2007;17(3):243-6.

29. Levine B, Della Valle CJ, Jacobs JJ. Applications of porous tantalum in total hip arthroplasty. J Am Acad Orthop Surg. 2006;14(12):646-55.

30. Lingaraj $\mathrm{K}$, Teo $\mathrm{YH}$, Bergman $\mathrm{N}$. The management of severe acetabular bone defects in revision hip arthroplasty using modular porous metal components. $J$ Bone Joint Surg Br. 2009;91(12):1555-60.

31. Jafari SM, Bender B, Coyle C, Parvizi J, Sharkey PF, Hozack WJ. Do tantalum and titanium cups show similar results in revision hip arthroplasty? Clin Orthop Relat Res. 2010;468(2):459-65.

32. Paulsen A, Pedersen AB, Johnsen SP, Riis A, Lucht U, Overgaard S. Effect of hydroxyapatite coating on risk of revision after primary total hip arthroplasty in younger patients: findings from the Danish Hip Arthroplasty Registry. Acta Orthop. 2007;78(5):622-8.

33. Lazarinis S, Kärrholm J, Hailer NP. Increased risk of revision of acetabular cups coated with hydroxyapatite. Acta Orthop. 2010;81(1):53-9.

34. Gandhi R, Davey JR, Mahomed NN. Hydroxyapatite coated femoral stems in primary total hip arthroplasty: a meta-analysis. J Arthroplasty. 2009;24(1):38-42.

35. Camazzola D, Hammond T, Gandhi R, Davey JR. A randomized trial of hydroxyapatite-coated femoral stems in total hip arthroplasty: a 13-year follow-up. J Arthroplasty. 2009;24(1):33-7. 